\title{
Changes in endometrial vascular permeability during the periimplantation period in the ferret (Mustela putorius)
}

\author{
R. A. Mead, S. Bremner and B. D. Murphy* \\ Department of Biological Sciences, University of Idaho, Moscow, Idaho 83843, U.S.A. \\ and ${ }^{*}$ Department of Biology, University of Saskatchewan, Saskatoon, Saskatchewan, \\ Canada S7N OWO
}

\begin{abstract}
Summary. A highly localized increase in permeability of uterine blood vessels in the immediate vicinity of implanting blastocysts was first detected on the morning of the 12 th day of pregnancy $(290 \mathrm{~h}$ post coitum $)$. The amount of extravasated dye which accumulated at implantation sites continued to increase through the evening of Day 13 ( $321 \mathrm{~h}$ p.c.). Blastocyst expansion, as indicated by small uterine swellings, preceded a detectable change in vascular permeability by about $10 \mathrm{~h}$, suggesting that the timing of increased permeability is closely associated with initial blastocyst attachment to the uterine epithelium.

The results do not support the hypothesis that prostaglandins are required for increased uterine vascular permeability as two doses of indomethacin (4 and $8 \mathrm{mg} / \mathrm{kg}$ body wt) administered 5 times/day failed to decrease endometrial vascular permeability. However, the $8 \mathrm{mg}$ dose did cause a significant reduction in size and number of uterine swellings and delayed or inhibited attachment of the trophoblast to the uterine epithelium in 2 of 5 ferrets. These findings suggest that prostaglandins play an important role in the process of implantation that is unrelated to decidual formation as the ferret is an adeciduate species.
\end{abstract}

Keywords: ferret, implantation, uterine vascular permeability, indomethacin

\section{Introduction}

One of the earliest recognizable events in blastocyst implantation in rodents and lagomorphs is a localized increase in endometrial vascular permeability which is readily demonstrated by intravenous injection of Evans blue dye. The dye becomes bound to a blood protein and subsequently seeps from post-capillary venules in the immediate vicinity of implanting blastocysts, resulting in a series of uniformly spaced blue bands that are visible upon gross inspection of the uterus. The localized uterine blueing is believed to occur in response to an implanting blastocyst (Psychoyos, 1960; Orsini, 1963; McLaren, 1969; Ljungkvist \& Nilsson, 1974; Hoffman et al., 1978) but also occurs in response to an artificial deciduogenic stimulus (Psychoyos, 1973; Kennedy, 1979). Prostaglandins and histamine are known to be involved in induction of uterine vascular permeability but other vasoactive substances have also been implicated (Brandon \& Wallis, 1977; Kennedy, 1980).

The localized increase in endometrial vascular permeability has been suggested to be a prerequisite for decidualization (Psychoyos, 1973; Peleg \& Lindner, 1982). Administration of indomethacin results in inhibition of uterine vascular permeability and reduction in weight of implantation sites in rats (Kennedy, 1977; Phillips \& Poyser, 1981) and hamsters (Evans \& Kennedy, 1978), the weight reduction presumably being due to inhibition of decidualization (Castracane et al., 1974). Sheep and pigs lack decidual tissue; however, they also exhibit increased endometrial capillary permeability at approximately the same time the embryos attach to the uterine epithelium (Boshier, 
1970; Keys et al., 1986). This investigation was initiated to determine whether increased endometrial vascular permeability occurred in a carnivore such as the ferret, which is also an adeciduate species and, if so, to relate the time course of this event to implantation. A second objective of this study was to test the hypothesis that inhibition of prostaglandin synthesis would prevent or significantly reduce vascular permeability at implantation sites and delay blastocyst implantation in the ferret.

\section{Materials and Methods}

Sixteen sexually mature ferrets (Mustela putorius) ranging in weight from 510 to $850 \mathrm{~g}$ were mated twice to different males within a 6 -h period. For the purpose of timing pregnancy, coitus was assumed to have occurred $0.5 \mathrm{~h}$ after placement with the first male and the day of mating was designated as Day 0. Four females were anaesthetized with pentobarbitone sodium $(30 \mathrm{mg} / \mathrm{kg})$ at each of the following times post coitum (p.c.): $279,290,312$ and $321 \mathrm{~h}$. The jugular vein of each female was surgically exposed and injected with $1.0 \mathrm{ml}$ of a $1 \%$ solution of Evans blue dye in $0.9 \%$ $(\mathrm{w} / \mathrm{v}) \mathrm{NaCl} / 700 \mathrm{~g}$ body weight. After $15 \mathrm{~min}$ the posterior half of each female was perfused via the heart with $250 \mathrm{ml}$ $0.9 \%(\mathrm{w} / \mathrm{v}) \mathrm{NaCl}$ and all uterine swellings (presumptive implantation sites) were excised and processed. Vascular permeability ratios were computed precisely as described by Judah \& Willoughby (1962) and Hoos \& Hoffman (1980). A few uterine swellings were processed individually but most were paired to provide higher absorbance readings, which were taken on a Gilford spectrophotometer. Results are expressed as the ratio of the concentration of Evans blue dye/mg tissue in the implantation site to that found in the adjacent 'non-implanted' uterus. The width of each uterine swelling was measured with calipers. Uteri lacking implantation sites were visually inspected for discrete areas of blue dye accumulation and then flushed with warm Medium TC 199. The diameter of each non-implanted blastocyst was measured with a calibrated ocular micrometer and the condition of each embryo was noted.

Pseudopregnancy was induced in 3 oestrous ferrets by injecting 100 i.u. hCG (i.p.). At 321 h after injection, each of these females was injected with Evans blue dye and their uteri were examined for evidence of localized sites of increased vascular permeability. Pseudopregnancy was confirmed in all females by observation of corpora lutea.

To test the hypothesis that prostaglandins are involved in the induction of increased endometrial vascular permeability, 30 additional ferrets, mated as described above, were randomly assigned to one of 3 groups. Each female received 5 subcutaneous injections $/ 24 \mathrm{~h}$, consisting of $0.4 \mathrm{ml} 20 \%$ ethanol in sesame oil $(\mathrm{N}=10)$ or indomethacin dissolved in $20 \%$ ethanol in seasme oil at a dose of $4 \mathrm{mg} / \mathrm{kg}$ body weight $(\mathrm{N}=10)$ or $8 \mathrm{mg} / \mathrm{kg}$ body weight $(\mathrm{N}=10)$. The injections began at 10:00 h on Day 11 (268 h p.c.) and were repeated at about $4 \cdot 5-\mathrm{h}$ intervals. The final injection was administered to 5 females from each of the 3 groups at $05: 30 \mathrm{~h}$ on Day 13 . The remaining 5 females in each treatment group received their last injections at $14: 30 \mathrm{~h}$ on Day 13. Each ferret was anaesthetized with pentobarbitone sodium, 3-6h later for the $312-315 \mathrm{~h} \mathrm{p.c.} \mathrm{group} \mathrm{or} 0.5-3.5 \mathrm{~h}$ later for the $321-324 \mathrm{~h}$ p.c. group, and $1.5 \mu \mathrm{Ci}$

${ }^{125} \mathrm{I}$-labelled bovine serum albumin (BSA)/100 g body weight were injected into the jugular vein along with $1.0 \mathrm{ml}$ Evans blue dye. After $15 \mathrm{~min}$, each animal was bled by cardiac puncture, the uterus removed and the adhering fat and mesentery removed. Each uterine swelling was measured and the spacing of the presumptive implantation sites was noted. Changes in endometrial capillary permeability were quantitated using the ${ }^{125} \mathrm{I}-\mathrm{labelled}$ BSA technique described by Psychoyos (1961). Results are expressed as the average ratio of c.p.m. of ${ }^{125} \mathrm{I} / \mathrm{mg}$ tissue in the presumptive implantation sites to c.p.m. of ${ }^{125} \mathrm{I} / \mathrm{mg}$ tissue obtained from the adjacent 'non-pregnant' uterus.

The data were statistically evaluated using the general linear models analysis of variance followed by Duncan's new multiple range test.

\section{Results}

Small uterine swellings averaging $4.0 \mathrm{~mm}$ in diameter were observed in uteri of 2 of 4 females at $279 \mathrm{~h}$ p.c. but no localized uterine blue colour was present at these sites at this time. Implantation had not yet occurred as expanding zona-encased blastocysts, ranging from 1.5 to $2.5 \mathrm{~mm}$ in diameter and averaging $2.2 \mathrm{~mm}$, were flushed from the uterine horns of all 4 females. The zona pellucida was fragile as evidenced by the finding of 3 empty zonae pellucidae and 3 nude blastocysts in uterine flushings of one animal that exhibited small uterine swellings.

Implantation sites, which averaged $4.7 \mathrm{~mm}$ in width, were present in all 4 ferrets examined at $290 \mathrm{~h}$ p.c. The majority $(60 \%)$ of individual or pairs of uterine swellings in each female had a vascular permeability ratio $>1.0$ (Table 1 ). However, a well defined accumulation of blue dye over the uterine swellings was only visible in 1 of 4 ferrets examined at this time.

By $312 \mathrm{~h}$ p.c., $70 \%$ of all implantation sites, which averaged $5.6 \mathrm{~mm}$ in width, exhibited a permeability ratio $>1 \cdot 0$. The average permeability ratio for all sites $(1 \cdot 24)$ was nearly $100 \%$ greater 
Table 1. Changes in endometrial vascular permeability during the peri-implantation period in ferrets as determined by the extravasation of Evans blue dye

\begin{tabular}{lccc}
\hline & $\begin{array}{c}\text { No. with } \\
\text { uterine } \\
\text { swellings }\end{array}$ & $\begin{array}{c}\text { Permeability } \\
\text { ratio }\end{array}$ & $\begin{array}{c}\text { Width of } \\
\text { uterine swellings } \\
\text { (mm) }\end{array}$ \\
Time p.c. & $2 / 4$ & $0 \cdot 64 \pm 0.25^{\mathrm{b}}(4)$ & $4 \cdot 0 \pm 0 \cdot 1^{\mathrm{c}}$ \\
\hline Day 11 p.m. $(279 \mathrm{~h})$ & $4 / 4$ & $1 \cdot 20 \pm 0 \cdot 71^{\mathrm{b}}(20)$ & $4 \cdot 7 \pm 0 \cdot 4^{\mathrm{c}}$ \\
Day 12 a.m. $(290 \mathrm{~h})$ & $1 \cdot 24 \pm 0 \cdot 53^{\mathrm{b}}(18)$ & $5 \cdot 6 \pm 0 \cdot 6^{\mathrm{b}}$ \\
Day 13 a.m. $(312 \mathrm{~h})$ & $4 / 4$ & $1.92 \pm 0.85^{\mathrm{a}}(19)$ & $6 \cdot 4 \pm 0 \cdot 3^{\mathrm{a}}$ \\
\hline Day 13 p.m. (321 h) & $4 / 4$ & $1.92 \pm 0 \cdot 4$ \\
\hline
\end{tabular}

Values are mean \pm s.d. Numbers in parentheses represent the number of pairs of implantation sites analysed. Values in the same column with different superscripts are statistically different $(P<0.05)$.

Table 2. Effect of indomethacin (ID) on endometrial vascular permeability on Day 13 of pregnancy in the ferret as determined by extravasation of ${ }^{125} \mathrm{I}$-labelled bovine serum albumin

\begin{tabular}{llcccc}
\hline & & \multirow{2}{*}{$\begin{array}{c}\text { No. with } \\
\text { uterine }\end{array}$} & Permeability & \multicolumn{2}{c}{ Implantation sites } \\
\cline { 4 - 6 } & Treatment & swellings & ratio & Number & Width (mm) \\
\hline 312 h p.c. & Sesame oil & $3 / 5$ & $1 \cdot 24 \pm 0 \cdot 07^{\mathrm{a}}(9)$ & $9 \cdot 7 \pm 2 \cdot 3^{\mathrm{a}}$ & $5 \cdot 9 \pm 0 \cdot 2^{\mathrm{a}}$ \\
& 4 mg ID & $5 / 5$ & $1 \cdot 26 \pm 0 \cdot 15^{\mathrm{a}}(15)$ & $9 \cdot 6 \pm 1 \cdot 8^{\mathrm{a}}$ & $5 \cdot 5 \pm 0 \cdot 3^{\mathrm{a}}$ \\
& 8 mg ID & $5 / 5$ & $1 \cdot 29 \pm 0 \cdot 16^{\mathrm{a}}(15)$ & $10 \cdot 3 \pm 3 \cdot 1^{\mathrm{a}}$ & $5 \cdot 1 \pm 0 \cdot 6^{\mathrm{a}}$ \\
$321 \mathrm{~h}$ p.c. & Sesame oil & $5 / 5$ & $1 \cdot 64 \pm 0 \cdot 19^{\mathrm{a}}(48)$ & $9 \cdot 6 \pm 1 \cdot 5^{\mathrm{a}}$ & $5 \cdot 7 \pm 0 \cdot 6^{\mathrm{a}}$ \\
& 4 mg ID & $5 / 5$ & $1 \cdot 53 \pm 0 \cdot 36^{\mathrm{a}}(38)$ & $7 \cdot 6 \pm 2 \cdot 1^{\mathrm{a}}$ & $4 \cdot 5 \pm 0 \cdot 4^{\mathrm{b}}$ \\
& 8 mg ID & $5 / 5$ & $1 \cdot 69 \pm 0 \cdot 36^{\mathrm{a}}(33)$ & $6 \cdot 6 \pm 1 \cdot 5^{\mathrm{b}}$ & $\mathbf{4} \cdot 4 \pm 0 \cdot 5^{\mathrm{b}}$ \\
\hline
\end{tabular}

Values are mean \pm s.d. Numbers in parentheses represent the numbers of pairs $(312 \mathrm{~h})$ or individual $(321 \mathrm{~h})$ uterine swellings analysed. Values in the same column with different superscripts are statistically different $(P<0.05)$.

than at $279 \mathrm{~h}$ p.c. Uteri of all 4 females exhibited well developed blue bands immediately over most implantation sites.

By $321 \mathrm{~h}$ p.c. all uterine swellings of all 4 ferrets averaged $6.4 \mathrm{~mm}$ in width and had a vascular permeability ratio $>1.0$. The average permeability ratio $(1.92)$ was greater than at ather time periods tested $(P<0.05)$. However, considerable variation was noted in the ratio, which ranged from $1 \cdot 12$ to $3 \cdot 86$.

No localized blue bands were observed in uteri of any pseudopregnant ferrets examined at $321 \mathrm{~h}$ p.c. Pseudopregnancy was confirmed in all 3 females by the presence of corpora lutea.

Nearly all animals (13/15) killed on the morning of Day $13(312-315 \mathrm{~h}$ p.c.) exhibited uterine swellings with blue bands over them. The 2 control animals which lacked implantation sites were pseudopregnant. However, neither dose of indomethacin ( 4 or $8 \mathrm{mg} / \mathrm{kg}$ administered 5 times/day) significantly reduced endometrial vascular permeability $(P>0.05)$ at the site of blastocyst implantation (Table 2). All presumptive implantation sites except one site from each of 2 animals that received $8 \mathrm{mg}$ indomethacin $/ \mathrm{kg}$ had vascular permeability ratios in excess of 1 . Moreover, all implantation sites were evenly spaced, suggesting that the presumed suppression of prostaglandin synthesis was not detrimental to this process. Blastocyst attachment to the uterine epithelium was verified by examination of histological sections of a single implantation site in 3 of 5 females in each indomethacin treated group, but could not be confirmed in the remaining 4 females. The largest dose of indomethacin caused a slight but non-significant $(P=0.75)$ reduction in size of uterine swellings but had no effect on the number of implantation sites (Table 2). 
All 15 females killed in the afternoon of Day $13(321-324 \mathrm{~h}$ p.c.) possessed evenly spaced implantation sites with blue bands over them. Neither dose of indomethacin significantly reduced the vascular permeability ratio $(P=0.367)$; however, both doses reduced the width of the uterine swellings $(P<0.05$, Table 2$)$. Trophoblastic attachment or invasion of the uterine epithelium was confirmed in a single implantation site in all animals that received sesame oil only and in each of 4 of 5 females receiving the $4 \mathrm{mg}$ dose of indomethacin. Remains of an empty zona pellucida were observed within the uterine swelling of the fifth ferret. On the other hand, only 3 of 5 females receiving the $8 \mathrm{mg}$ dose exhibited trophoblastic penetration of the uterine epithelium. Zona-free, unattached, bilaminar blastocysts, all of which were collapsed, were observed in uteri of the remaining 2 females. The $8 \mathrm{mg}$ dose of indomethacin resulted in significantly fewer uterine swellings $(P<0.05$, Table 2$)$ than in the other treatment groups.

\section{Discussion}

An increase in capillary permeability appears to be a common event in the process of implantation as it has now been documented in the rat (Psychoyos, 1960), hamster (Orsini, 1963), mouse (Orsini \& McLaren, 1967), rabbit (Hoffman et al., 1978), ewe (Boshier, 1970), sow (Keys et al., 1986) and ferret. In the ferret, loss of the zona pellucida, adhesion and attachment of the trophoblast to the uterine epithelium occur between Days 12 and 13 (Enders \& Schlafke, 1972) or about 288-312 h p.c. In the present study, small uterine swellings were visible at $279 \mathrm{~h}$ p.c. $(10-11 \mathrm{~h}$ before any detectable increase in endometrial vascular permeability) and consistently had a permeability ratio of less than 1. This unexpected finding may have resulted from venous congestion in sections of uterus between implantation sites and a somewhat restricted blood flow at uterine swellings due to rapid expansion of the blastocyst. Therefore vasodilatory substances might be released to increase blood flow to the implantation sites.

Localized accumulation of blue dye over uterine swellings was first observed on the morning of Day $12(290 \mathrm{~h}$ p.c.) in 1 of 4 females, whereas all ferrets exhibited a uterine blueing response by the morning of Day 13 ( $312 \mathrm{~h}$ p.c.). Consequently, the timing of the increase in capillary permeability in the ferret uterus appears to be temporally correlated with blastocyst attachment and early penetration of the uterine epithelium. Wu \& Chang (1972), however, reported observing uterine blueing at 10 days and $23 \mathrm{~h}$, at which time the blastocysts were still surrounded by the zona, and is thus contrary to our findings of no uterine blueing at $279 \mathrm{~h}$ p.c. (evening of Day 11).

Absence of a localized accumulation of blue dye in uteri of pseudopregnant ferrets and the fact that uterine blueing was only observed directly over implantation sites suggests that the increase in vascular permeability occurred in response to the blastocyst or to substances released from it. The latter seems possible, as localized uterine swellings produced by expanding ferret blastocysts were observed $10 \mathrm{~h}$ before any detectable increase in vascular permeability. This suggests that the initial pressure on the endometrium, exerted by expanding blastocysts, is not responsible for stimulating release of vasoactive substances from the uterus. Moreover, some ferrets that received indomethacin exhibited an extravasation of blue dye in areas immediately over blastocysts which had failed to expand sufficiently to induce noticeable uterine swellings. Evans \& Kennedy (1980) have suggested that the localized elevation of concentrations of prostaglandin $\mathrm{E}$ observed at implantation sites in hamsters were induced by a blastocyst signal that was independent of blastocyst steroidogenesis. However, it remains to be demonstrated that ferret blastocysts are capable of secreting vasoactive substances as has been reported for the rabbit (Dey et al., 1979, 1980; Harper et al., 1983; Racowsky \& Biggers, 1983), mouse (Dey \& Johnson, 1980) and sheep (Lacroix \& Kann, 1982).

Our failure to reduce endometrial vascular permeability in ferrets treated with indomethacin cannot readily be explained by breakdown of this drug before injection as preweighed aliquants were solubilized about $15-20 \mathrm{~min}$ before injection. It is also unlikely that our negative results are 
due to an inadequate injection schedule as indomethacin administration began $28 \mathrm{~h}$ before the earliest time we detected increased vascular permeability and continued until $0.5-6 \mathrm{~h}$ prior to termination of the experiment. Moreover, injections were administered at approximately $4 \cdot 5-h$ intervals which is equivalent to the reported biological half-life of indomethacin (Kwan et al., 1978). It is also questionable whether our negative results are due to insufficient dosage as significant decreases in size and number of implantation sites, and a slight delay or inhibition of implantation, were noted in 2 of 5 females when $8 \mathrm{mg}$ indomethacin/ $\mathrm{kg}$ body weight were administered. This same dose of indomethacin also produced a reduction in size of uterine swellings and delayed implantation, but also inhibited uterine blueing in rabbits (Hoffman et al., 1978), whereas $10 \mathrm{mg} / \mathrm{kg}$ were lethal (Snabes \& Harper, 1984). Experiments by Snabes \& Harper (1984) suggest that indomethacin acts predominantly on the uterus rather than the blastocyst to inhibit implantation in the rabbit. Our results indicate that indomethacin was exerting many of the same biological effects in ferrets, suggesting that the observed effects resulted from reduced prostaglandin levels. If the above interpretation is correct it would indicate that prostaglandins play an important role in blastocyst implantation in ferrets and perhaps in other adeciduate species such as pigs (Kraeling et al., 1985). On the other hand, Lacroix \& Kann (1982) reported that a single $300 \mathrm{mg}$ injection of indomethacin each day resulted in a marked reduction in endometrial PGE and PGF concentrations with no ill effects on establishment of pregnancy in ewes. Our results clearly indicate that increased vascular permeability occurs in the ferret and is temporally correlated with the final stage of blastocyst expansion and attachment to the uterine epithelium. Our failure to suppress endometrial vascular permeability with indomethacin, a well documented inhibitor of prostaglandin synthesis, suggests that other vasoactive substances are involved in increasing vascular permeability at the time of implantation in the ferret. The data also suggest that prostaglandins play an important role in the initial stages of blastocyst implantation in adeciduate species that are unrelated to decidual formation or vascular permeability.

We thank Ron May, Matt Berria, Patrice Henderson, M. Joseph and Sandra Neirinckx for their help in collecting and processing the tissue samples. This work was supported by grants from the NIH HD 06556 (to R.A.M.) and NSERC A9743 (to B.D.M.)

\section{References}

Boshier, D.P. (1970) The pontamine blue reaction in pregnant sheep uteri. J. Reprod. Fert. 22, 595-596.

Brandon, J.M. \& Wallis, R.M. (1977) Effect of mepyramine, a histamine $\mathrm{H}_{1}-$, and burimamide, a histamine $\mathrm{H}_{2}$-receptor antagonist, on ovum implantation in the rat. J. Reprod. Fert. 50, $251-254$.

Castracane, V.D., Saksena, S.K. \& Shaikh, A.A. (1974) Effect of IUDs, prostaglandins and indomethacin on decidual cell reaction in the rat. Prostaglandins 6, $397-404$.

Dey, S.K. \& Johnson, D.C. (1980) Histamine formation by mouse preimplantation embryos. J. Reprod. Fert. 60, $457-460$.

Dey, S.K., Johnson, D.C. \& Santos, J.G. (1979) Is histamine production by the blastocyst required for implantation in the rabbit? Biol. Reprod. 21, 1169-1174.

Dey, S.K., Chien, S.M., Cox, C.L. \& Crist, R.D. (1980) Prostaglandin synthesis in the rabbit blastocyst. Prostaglandins 19, 449453.

Enders, A.C. \& Schlafke, S. (1972) Implantation in the ferret: epithelial penetration. Am. J. Anat. 133, 291-316.
Evans, C.A. \& Kennedy, T.G. (1978) The importance of prostaglandin synthesis for the initiation of blastocyst implantation in the hamster. $J$. Reprod. Fert. 54, 255-261.

Evans, C.A. \& Kennedy, T.G. (1980) Blastocyst implantation in ovariectomized, adrenalectomized hamsters treated with inhibitors of steroidogenesis during the pre-implantation period. Steroids 36, 41-52.

Harper, M.J.K., Norris, C.J. \& Rajkumar, K. (1983) Prostaglandin release by zygotes and endometria of pregnant rabbits. Biol. Reprod. 28, 350-362.

Hofiman, L.H., DiPietro, D.L. \& McKenna, T.J. (1978) Effects of indomethacin on uterine capillary permeability and blastocyst development in rabbits. Prostaglandins 15, 823-828.

Hoos, P.C. \& Hoffman, L.H. (1980) Temporal aspects of rabbit uterine vascular and decidual responses to blastocyst stimulation. Biol. Reprod. 23, 453- 459.

Judah, J.D. \& Willoughby, D.A. (1962) A quantitative method for the study of capillary permeability: extraction and determination of trypan blue in tissues. J. Pathol. Bacteriol. 83, 567-572.

Kennedy, T.G. (1977) Evidence for a role for prosta- 
glandins in the initiation of blastocyst implantation in the rat. Biol. Reprod. 16, 286-291.

Kennedy, T.G. (1979) Prostaglandins and increased endometrial vascular permeability resulting from the application of an artificial stimulus to the uterus of the rat sensitized for the decidual cell reaction. Biol. Reprod. 20, $560-566$.

Kennedy, T.G. (1980) Prostaglandins and the endometrial vascular permeability changes preceding blastocyst implantation and decidualization. Prog. Reprod. Biol. 7, 234-243.

Keys, J.L., King, G.J. \& Kennedy, T.G. (1986) Increased uterine vascular permeability at the time of embryonic attachment in the pig. Biol. Reprod. 34, 405-411.

Kraeling, R.R., Rampacek, G.B. \& Fiorello, N.A. (1985) Inhibition of pregnancy with indomethacin in mature gilts and prepuberal gilts induced to ovulate. Biol. Reprod. 32, 105-110.

Kwan, K.C., Breault, G.O., Davis, R.L., Lei, B.W., Czerwinski, W.W., Besselaar, G.H. \& Duggan, D.E. (1978) Effects of concomitant aspirin administration on the pharmacokinetics of indomethacin in man. $J$. Pharmacokinet. Biopharm. 6, 451-476.

Lacroix, M.C. \& Kann, G. (1982) Comparative studies of prostaglandins $F_{2 a}$ and $E_{2}$ in late cyclic and early pregnant sheep: in vitro synthesis by endometrium and conceptus effects of in vivo indomethacin treatment on establishment of pregnancy. Prostaglandins $23,507-526$.

Ljungkvist, I. \& Nilsson, O. (1974) Blastocyst-endometrial contact and pontamine blue reaction during normal implantation in the rat. $J$. Endocr. 60, 149-154.

McLaren, A. (1969) Can mouse blastocysts stimulate a uterine response before losing the zona pellucida? $J$. Reprod. Fert. 19, 199-201.
Orsini, M.W. (1963) Morphological evidence on the intrauterine career of the ovum. In Delayed Implantation, pp. 155-166. Ed. A. C. Enders. University of Chicago Press, Chicago.

Orsini, M.W. \& McLaren, A. (1967) Loss of the zona pellucida in mice, and the effect of tubal ligation and ovariectomy. J. Reprod. Fert. 13, 485-499.

Peleg, S. \& Lindner, H.R. (1982) The effect of prostaglandins on progestin receptor translocation and on decidual cell reaction in vivo and in vitro. Endocrinology 110, 1647-1652.

Phillips, C.A. \& Poyser, N.L. (1981) Studies on the involvement of prostaglandins in implantation in the rat. J. Reprod. Fert. 62, 73-81.

Psychoyos, A. (1960) Nouvelle contribution à l'étude de la nidation de l'oeuf chez la ratte. C. r. hebd. Séanc. Acad. Sci. Paris D 251, 3073-3075.

Psychoyos, A. (1961) Perméabilité capillaire et décidualisation utérine. C. r. hebd. Séanc. Acad. Sci. Paris D 252, 1515-1517.

Psychoyos, A. (1973) Endocrine control of egg implantation. In Handbook of Physiology, Section 7, Vol. II, Part 2, pp. 187-215. Eds R. O. Greep, E. G. Astwood \& S. R. Geiger. Am. Physiol. Soc., Washington, D.C.

Racowsky, C. \& Biggers, J.D. (1983) Are blastocyst prostaglandins produced endogenously? Biol. Reprod. 29, 379-388.

Snabes, M.C. \& Harper, M.J.K. (1984) Site of action of indomethacin on implantation in the rabbit. $J$. Reprod. Fert. 71, 559-565.

Wu, J.T. \& Chang, M.C. (1972) Effects of progesterone and estrogen on the fate of blastocysts in ovariectomized pregnant ferrets: a preliminary study. Biol. Reprod. 7, 231-237.

Received 27 May 1987 